\title{
Concrete Formation Using Fiber and Polymer
}

\author{
Vikas Rohal $^{1}$, Gaurav Kumar ${ }^{2}$ \\ ${ }^{1}$ M.Tech. Student, Department of Civil Engineering, NNSS SAmalkha Group of Institutions, Department of Civil Engineering, Affiliated to \\ Kurukshetra University, Kurukshetra, Haryana, India
}

${ }^{2} \mathrm{HOD}$, Department of Civil Engineering, NNSS SAmalkha Group of Institutions, Department of Civil Engineering, Affiliated to Kurukshetra University, Kurukshetra, Haryana, India

\begin{abstract}
The use of fibres in brittle matrix materials has a long history going back at least 3500 years when sun-baked bricks reinforced with straw were used to build the $57 \mathrm{~m}$ high hill of Aqar Quf near Baghdad. In more recent times, asbestos fibres have been used to reinforce cement products for about 100 years, cellulose fibres for at least 50 years, and polypropylene, steel and glass fibres have been used for the same purpose for the past 30 years. The importance of fiber reinforcement is to carry the load along its length and also to provide stiffness and strength in one direction. Fibre reinforced polymer in this manner modify the compressive strength, tensile strength and flexural strength of concrete in a good amount and hence it sign as a good solution for enrichment concrete. Fibre reinforced polymer materials may be externally bonded or wrapped to the parent structure; hence they can be used for re-establishment works. In the present investigation he effect of Polyester fibre (Polymer at dosage of 0\%, 0.3\%, 0.6\%, 0.9\%, $1.2 \%$ of cement) for compressive strength, flexural strength and split tensile strength of M25 concrete and test were carried out on basis of recommended codes for 7 days, 28 days and 90 days.
\end{abstract}

Keywords: fiber, polymer, compressive strength

\section{Introduction}

The rapid increase in sophistication of design and construction techniques and greater attention to variation in regional and local conditions has created a demand for modification of certain properties of concrete. This has resulted in the development of several "types" of Portland cement and a greater use of concrete admixtures. These types have extensive use in the precast and ready-mix concrete industries. The production of a different type of Portland cement involves certain adjustments in the manufacturing process, mainly the selection of raw materials, chemical proportions, special additives and the degree of grinding. The inevitable increase in cost of these modified Portland cements over the normal product is due partly to the above adjustments in manufacture and partly to additional handling and storage requirements in the plant. Precision cut Polyester fibre is a very strong and stable manmade fibre that is widely used in many industries. Polyester is resistant to stretching and shrinking and perhaps more importantly for industrial applications it is resistant to abrasion and acid degradation. Polyester has a relatively high specific gravity, leading to it dispersing well in water and a relatively high melting point making it a good all round choice for a variety of applications. In India, research is also going on to utilize huge stock

\section{Background}

Polymer concrete is a material which does not contain an inorganic binder. The binder or matrix in polymer composites is a synthetic resin. According to the resin type used, it is possible to classify polymer concretes as epoxy, polyester, acrylic, polyurethane, etc. Polymer concrete is a heterogeneous material. As a result, the properties of polymer concrete may be highly variable.

The use of fibres in brittle matrix materials has a long history going back at least 3500 years when sun-baked bricks reinforced with straw were used to build the $57 \mathrm{~m}$ high hill of Aqar Quf nearBaghdad, Iraq. A pueblohouse constructed around 1540, created to be the oldest house in theUnitied States, is constructed of sunbaked adobe reinforced with straw.

Fibre Reinforced Concrete (FRC) was invented by French gardener Joseph Monier in 1849 and patented in 1867. The concept of using fibres as reinforcement is not new. This can be proved by the following:

Fibres have been used as reinforcement since ancient times. In the past horsehair was used in mortar and straw in mud bricks. In the early 1900s, asbestos fibres were used in concrete, and in the 1950s the knowledge of composite materials came into being and fibre reinforced concrete was one of the topics of interest. There was a requirement to find a replacement for the asbestos used in concrete and other building materials once the health risks associated with the substance were discovered. By the 1960s, glass (GFRC), steel, and synthetic fibres such as polypropylene fibres were used in concrete, and investigation for new fibre reinforced concretes continues today.

The main objectives of the modern engineer in attempting to modify the properties of concrete by the inclusion of fibres are as follows:

a) To improve the rheology or plastic cracking characteristics of the material in the fresh state or up toabout 6 hours after casting.

b) To improve the tensile or flexural strength.

c) To improve the impact strength and toughness.

d) To control cracking and the mode of failure by means of postcracking ductility.

e) To improve durability.

Fibre offer enhanced fracture toughness, increased tensile strength and minimized cracking behavior in various

\section{Volume 5 Issue 6, June 2016} www.ijsr.net 


\section{International Journal of Science and Research (IJSR) \\ ISSN (Online): 2319-7064 \\ Index Copernicus Value (2013): 6.14 | Impact Factor (2015): 6.391}

environments. When properly selected and employed, discrete fibers concrete matrix is internally reinforced in a three-dimensional network, limiting cracking to smallsized micro cracks. The inclusion of any type of short fibre in a three-dimensional random fibre distribution at practical fibre volumes will not significantly alter the load at which cracking occurs in hardened concrete.Historically speaking, fibers experimented in concrete were made of glass, steel, carbon ,polymers and other wide spectrum of natural and synthetic materials.

These fibers may be different not only in materials but also in their size, shape, aspect ratio and texture. The difference between conventional reinforcement and fibre reinforcement is that conventional reinforcement, bars are oriented in direction desired while fibre is provide randomly oriented.

A fiber has a length that is much greater than its diameter. The length-to-diameter ( $1 / \mathrm{d})$ ratio is known as the aspect ratio and can differ greatly. Continuous fibers have long aspect ratios whereas discontinuous fibers have short aspect ratios. Continuous- fiber composites normally have an ideal orientation, while discontinuous fibers generally have a random orientation.

Patterns ofcontinuous reinforcements include unidirectional, woven cloth, and helical twisting while patterns of discontinuous reinforcements are chopped fibers and random mat.

\section{Material Used For Study}

About $30 \%$ of all polymers produced each year are used in the civil engineering and building industries. Polymers offer many advantages over conventional materials including lightness, resilience to corrosion and ease of processing. They can be combined with fibres to form composites which have enhanced properties, enabling them to be used as structural members and units and their properties are very different from those of traditional ones such as concrete and metal.

Polymers made of a single type of monomer are called homopolymers while those made of different monomers constitute a copolymer. In the latter, the ratio and configuration of the individual monomers influence its properties. The important parameters influencing the properties of polymers are the rate of polymerization, the length of polymer chains, crystallinity and crosslinking and presence of additives.

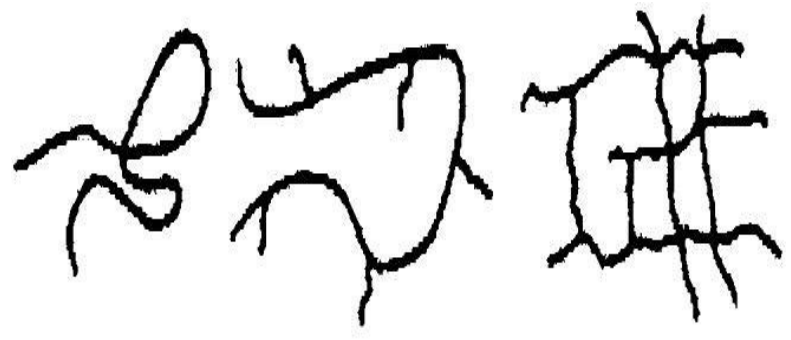

(a) Linear (b) Branched (c) Cross-linked

Polymers, generally, have lower thermal resistance than metals especially in the presence of oxygen. Among the common polymers, poly tetra fluoro ethylene has the highest thermal stablility due to the presence of strong C--C and C-F bonds. Thermoplastic polymers are those which when heated through a range of temperature change from rigid solids to highly viscous liquids. Thermosetting polymers on the contrary, do not soften but undergo contraction and charring at high temperatures.

\section{Test Program}

The prime objective of the study was to evaluate the structural properties of concrete containing polyester fibre and that of concrete containing with no polyester fibre of corresponding mix proportions.

Since it is an established fact that hydration of pozzolanic material is a delayed process compared to hydration of plain cement concrete, the main emphasis was to compare the relative structural properties of two types of the concrete at later ages. Moreover, polyester fibre used in this study was obtained from 'Reliance Industries'.

To establish its credential as a structural material, any type of concrete has to achieve the minimum acceptable criterion regarding the two most important structural properties viz. strength and durability. The present study is limited to the testing of strength of concrete.

Strength of concrete is considered its most valuable property although in different practical situations. Other characteristics such as durability, impermeability etc. may, in fact are more important. Nevertheless, the strength usually gives an overall picture of quality of concrete because strength is directly related to the structure of hardened cement paste.

To investigate the strength considerations the following tests were conducted:

1) Compressive strength test is the strength of concrete against crushing due to the direct compressive load. It is considered as most important property and often taken as the index of overall quality of concrete. Concrete has high compressive stress and it is normally required to resist compressive stresses. Compressive strength at 28 days after casting is taken as the criteria for specifying the quality of concrete

2) Flexural strength test

3) Split tensile strength test

\section{Result and Discussion}

The cubes and cylinder were tested for the compressive strength and beams specimens were tested for flexural strength. Splitting tensile strength tests were conducted on cylinder specimens. The total numbers of 54 cubes, 30 beams specimens and 45 numbers of cylinders were tested for compressive strength, flexural strength and splitting tensile strength respectively at different ages to study the following aspects:

1) To design the concrete mix of grade M25 with PPC cement with super plasticizer.

2) The effect of polyester fiber on workability of fresh concrete.

\section{Volume 5 Issue 6, June 2016 www.ijsr.net}




\section{International Journal of Science and Research (IJSR) \\ ISSN (Online): 2319-7064}

Index Copernicus Value (2013): 6.14 | Impact Factor (2015): 6.391

3) The effect on compressive, flexural and splitting tensile strength using polyester fiber in varying percentages of cement.

4) To study comparative variation strength in polyester fiber.

5) The effect is investigated on concrete using polyester fiber as an addition of cement content for the following levels:

1. Addition of polyester fiber by $0.3 \%$ cement content.

2. Addition of polyester fiber by $0.6 \%$ cement content.

3 . Addition of polyester fiber by $0.9 \%$ cement content.

4. Addition of polyester fiber by $1.2 \%$ cement content

\section{Splitting Tensile Strength of Concrete}

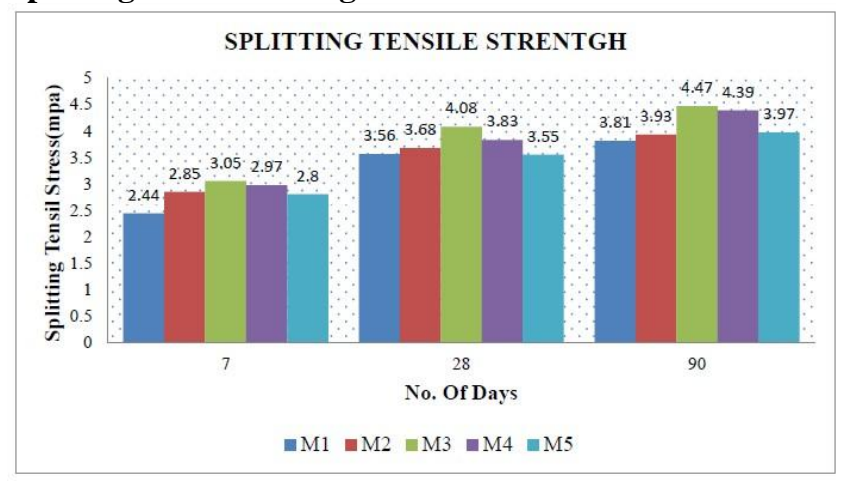

Polyester fiber concrete containing $0 \%$ fiber after 7 days, 28 days and 90 days was found to be having compressive strength $23.82 \mathrm{~N} / \mathrm{mm} 2,33.96 \mathrm{~N} / \mathrm{mm} 2$ and $41.11 \mathrm{~N} / \mathrm{mm} 2$ respectively. A gain in strength with age is observed.

The increase in strength is $42.56 \%$ at 28 days and increase of $72.58 \%$ is observed after 90 days. Polyester fiber concrete containing $0.3 \%$ fiber after 7 days, 28 days and 90 days was found to be having compressive strength $30.36 \mathrm{~N} / \mathrm{mm} 2$, $41.72 \mathrm{~N} / \mathrm{mm} 2$ and $46.95 \mathrm{~N} / \mathrm{mm} 2$ respectively.

A gain in strength with age is observed.

The increase in strength is $37.41 \%$ at 28 days and further increase of $54.64 \%$ is observed after 90 days. Polyester fiber concrete containing $0.6 \%$ fiber after 7 days, 28 days and 90 days was found to be having compressive strength $30.86 \mathrm{~N} / \mathrm{mm} 2,44.88 \mathrm{~N} / \mathrm{mm} 2$ and $52.23 \mathrm{~N} / \mathrm{mm} 2$ respectively. A gain in strength with age is observed. The increase in strength is $45.43 \%$ at 28 days and further increase of $69.24 \%$ is observed after 90 days.

Polyester fiber concrete containing $0.9 \%$ fiber after 7 days, 28 days and 90 days was found to be having compressive strength $31.64 \mathrm{~N} / \mathrm{mm} 2,46.06 \mathrm{~N} / \mathrm{mm} 2$ and $53.40 \mathrm{~N} / \mathrm{mm} 2$ respectively. A gain in strength with age is observed. The increase in strength is $45.57 \%$ at 28 days and increase of $68.77 \%$ is observed after 90 days.

Polyester fiber concrete containing 1.2\% fiber after 7 days, 28 days and 90 days was found to be having compressive strength $27.19 \mathrm{~N} / \mathrm{mm} 2,42.65 \mathrm{~N} / \mathrm{mm} 2$ and $48.70 \mathrm{~N} / \mathrm{mm} 2$ respectively. A gain in strength with age is observed.
The increase in strength is $56.85 \%$ at 28 days and increase of $79.10 \%$ is observed after 90 days. The compressive strength of concrete increase with addition of $\%$ cement with the polyester fiber. Because polyester fiber particle are softer than fine aggregates and it reduce micro crack

It is seen from the results that ' $\mathrm{M} 3$ ' mix type gives comparable flexural strength of $4.36 \mathrm{MPa}$ at the age of 90 days which can be used for pavement application. Results show that with the further increase in the polyester fibre percentage, the flexural strength goes on decreasing. The flexural strength of polyester fibre concrete decreases with the increase in replacement of the fine aggregates and at the same time it is seen that flexural strength of polyester fibre concrete increases with the age.

The reason behind the strength behaviour is same as that of compressive strength behaviour.

Moreover, the flexural strength is affected to more extent with the increase in polyester fibre content.

Hence it is concluded that the polyester fibre concrete gains flexural strength with the age and it is comparable but is still less than that of plain concrete, it is because of the fact that there is poor interlocking between the aggregates as polyester fibre particles are spherical in nature.

\section{Conclusion}

The following conclusions are drawn from the present study:

1) Early strength was observed in concrete containing polyester fiber after 7 days of curing.

2) The compressive strength of polyester fiber concrete increased with increase in percentage of polyester fiber with cement for $0.6 \%, 0.9 \%$ i.e. $69 \%$ and then gradually decreased with high dosage of $1.2 \%$.

3) The compressive strength and split tensile strength of polyester fiber concrete increased with increase in age i.e. the 90 days compressive strength and split tensile strength of polyester fiber concrete was found to be $15 \%-30 \%$ more as compared to the 28 days compressive strength. and tensile strength.

4) The flexural strength of $0.6 \%$ polyester fiber concrete increased with increase in age i.e. the 90 days compressive strength of polyester fiber concrete was found to be more as compared to the 28 days flexural strength.

5) After 28 days of curing polyester fiber concrete having $0.6 \%$ polyester fiber concentration gave more tensile strength than that of $10 \%$ polyester fiber concrete. But after 90 days of curing polyester fiber concrete having $10 \%$ polyester fiber concrete gave more tensile strength than that of $5 \%$ polyester fiber concrete.

6) The polyester fiber concrete having $0.6 \%$ polyester fiber concrete gave more flexural strength than that of 0 $.3 \%, 0.9$ and $1.2 \%$ polyester fiber concrete after 28 and 90 days of moist curing.

7) The Polyester fiber concrete having $0.9 \%$ having increase in compressive strength and in 28 days. But $0.6 \%$ having increase in flexure strength and split ensile strength. 


\section{International Journal of Science and Research (IJSR) \\ ISSN (Online): 2319-7064}

Index Copernicus Value (2013): 6.14 | Impact Factor (2015): 6.391

8) It can be concluded that concrete containing $0.6 \%$ and $0.9 \%$ of polyester fiber showed significant improvement in strength parameter as compared to conventional concrete. Hence cement can be used with $0.6 \%-0.9 \%$ of polyester fiber thereby reducing the environmental hazard and for making the concrete economical can be used 0.6 $\%$.

\section{References}

[1] Abou-Zeid, M. N., Fahmy E. H. and Massoud, M. T, "Interaction of Silica Fume and Polypropylene Fibers" in High Performance Concrete. 30th Annual Conference of the Canadian Society for Civil Engineering, Second Materials Symposium, Montreal,Canada, June 5-8, 2002

[2] AM Alkhaleefi, M EI·Hawary, H Abdel-Fattah, "On the behaviour of polymer portland cement concrete" in 27th Conference on Our world in concrete \& structures: 29 - 30 August 2002, Singapore. Article Online Id: 100027015 pp $137-144$.

[3] A.M.Neville, J.J.Brook in "Advance Concrete Technology", 2010.

[4] F.C.Cambell in "Structural Composite Materia", 2010.

[5] Faisal fouad wafa, "Properties and Applications of Fiber Reinforced Concrete, JKAU: Eng. Sci., Vol. 2, pp. 49-6 (1410

[6] A.H./191JII A.D.).

[7] Geethanjali C, Jaison Varghese, P Muthu Priya Influence of Hybrid Fiber on Reinforced Concrete in International journal of advance structure and geotechnical engineering, 2014 pp 40

[8] Inderjit Patel, C D Modhera, “ Experimental Investigation to Study Effect of Polyester Fibre on Durability" in JERS Vol.II Issue I on January-March 2011,pp 159-166

[9] Inderjit Patel, C D Modhera. Experimental Investigation to Study Effect of Polyester Fibre on Durability in IOSR journal of engineering (IOSRJEN), 2013 pp 22-27.

[10] Ingemar Lofgren, Fracture Behaviour of Reinforced FRC Beams experiments and Analyses in Structural Concrete, Journal of the fib, October 2005

[11] IS: 383-1970, “ IS specifications for coarse and fine aggregate from natural sources for concrete",Bureau of Indian Standards, New Delhi, 1997.

[12] IS $4 \quad 5 \quad 6 \quad-2000$ Code o $\mathrm{f}$ practice for plain and reinforced concrete. Bureau of Indian Standards, New Delhi, 2000.

[13] IS: 516- 1959, "Methods of tests for strength of concrete", Bureau of Indian Standards, New Delhi, 1999.

[14] IS: 1489(part 1):1991, "Specification for Portland pozzolana cement specification (fly ash based) ", Bureau of Indian Standards, New Delhi, 1991.

[15] IS: 2645:2003, "Specification for integral water proofing compounds”, Bureau of Indian Standards

\section{Author Profile}

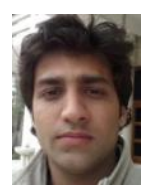

Vikas rohal is currently in final year $\mathrm{M}$ TECH Structural Engineering from Samalkha Group Of Instutions,Affilated to Kurukshetra University, Kurukshetra. He did B.TECH in Civil Engineering from NC College of engineering israna Affilated to kurekshetra university kuk.2013 (2009 Batch).He has 1 International Publications. His interested areas of research are, fiber and polymer concrete, green concrete. 